\title{
EFFECTS OF AN ANTIOESTROGEN ON THE CORPUS LUTEUM OF RABBITS AND RATS
}

\author{
A. P. LABHSETWAR \\ Imperial Chemical Industries Limited, Pharmaceuticals Division, \\ Alderley Park, Macclesfield, Cheshire
}

(Received 25th November 1970)

\begin{abstract}
Summary. The effects of a potent antioestrogen-ICI 46,474-on CL were examined in pregnant and pseudopregnant rabbits and pregnant rats. In the rabbit, the antioestrogen interfered with the growth of ca, reducing significantly both the number and weight of the glands. In the pregnant rat, the weight of the CL was reduced and this was associated with a marked stimulation of mammary glands. These experiments provide further evidence that CL in the rabbit, and perhaps in the rat, require oestrogen for their functional maintenance.
\end{abstract}

The mechanisms by which the corpus luteum (CL) is maintained in a functional state varies considerably from species to species (see Greenwald \& Rothchild, 1968). Robson (1937) first reported that the cL can be maintained by oestrogen in hypophysectomized rabbits. Since then, several authors have confirmed this observation using various techniques (Nalbandov, 1970). Some evidence indicates that oestrogen is also required for the maintenance of the CL in rats (Bogdanove, 1966). In view of these observations, it seemed of interest to examine the effects of an antioestrogen on the cL of rabbits and rats.

Adult Dutch-belted rabbits were purchased locally and individually caged in a room with constant temperature. Animals were provided with a standard diet but photoperiod was not controlled. Mated rabbits were dosed with a potent antioestrogen-IGI 46,474 (trans-1-( $p$ - $\beta$-dimethylaminoethoxyphenyl)1,2-diphenylbut-1-ene) from Days 1 to 9 (Day $1=$ day of mating). Pseudopregnancy was induced by intravenous injection of 25 i.u. HGG (Day I of pseudopregnancy) and rabbits were treated with the antioestrogen from Days 2 to 9 . This experiment was subsequently repeated. All rabbits were dosed orally $(2 \mathrm{mg} / \mathrm{kg} /$ day) with the antioestrogen made up in $0.5 \%$ aqueous Tween 80. Mated rats (Day $1=$ day of spermatozoa in the vaginal smear) received the same treatment from Days 10 to 20 . All animals were killed 1 day after the last injection. The cL were enucleated, counted and then weighed on a torsion balance.

In the pregnant rabbit (Exp. A, Table 1), the antioestrogen significantly reduced the luteal count and average weight of the CL. In the pregnant rat (Exp. B), the number of CL remained unchanged but the average weight of the GL was significantly reduced. Histologically, the cL of both species showed signs 


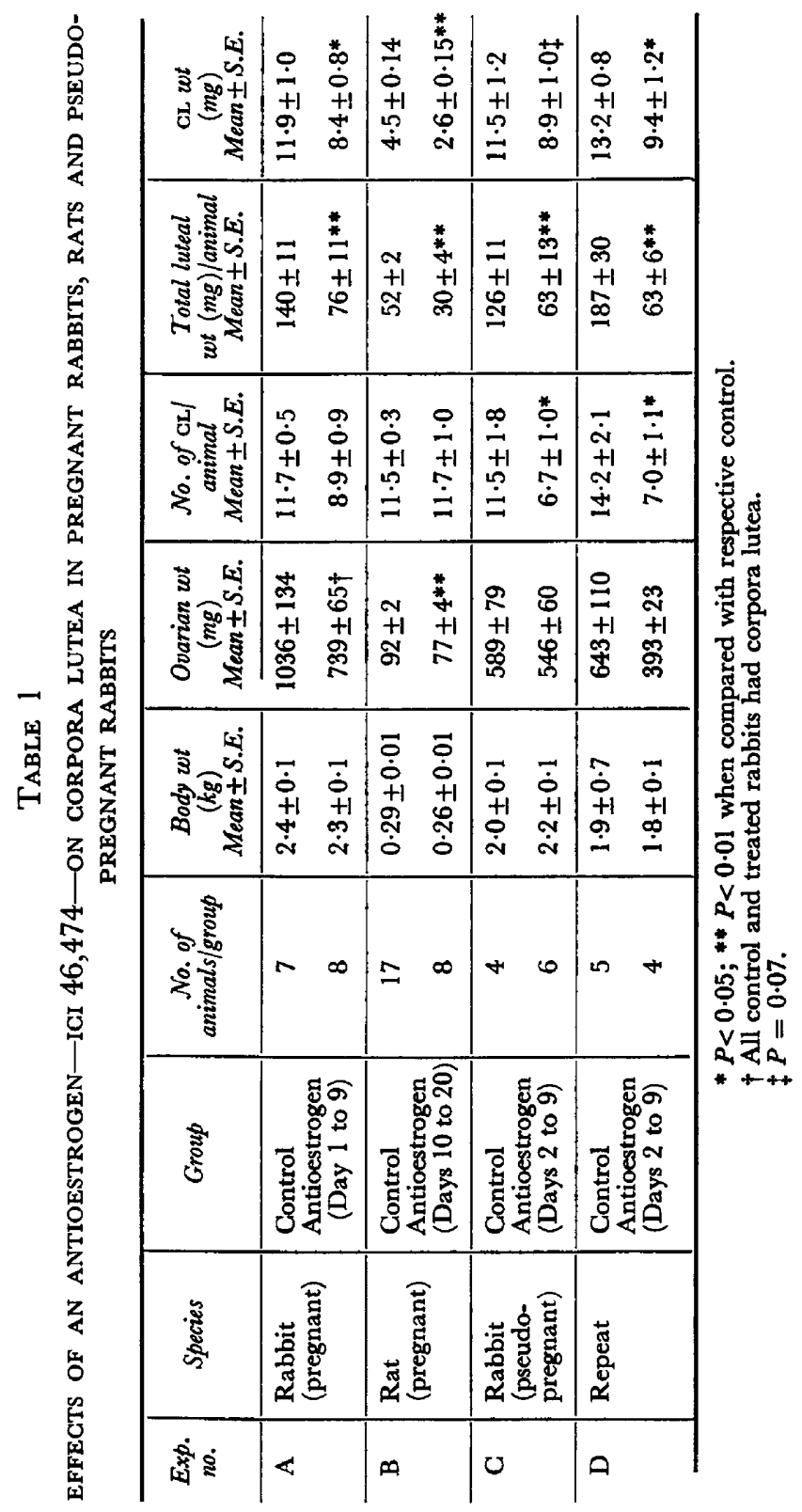


of degeneration, luteal tissue showing infiltration with fibroblasts and many luteal cells having pycnotic nuclei. The mammary glands of the pregnant rats treated with the antioestrogen were markedly stimulated. The alveolar density was increased; many alveoli were dilated and showed signs of secretion. In the control pregnant rats, on the other hand, the alveoli were sparse and lactogenesis was absent. After the completion of these experiments, Kuhn (1969) reported that initiation of lactogenesis in rats requires withdrawal of progesterone, as normally occurs following parturition. Thus, lactogenesis in the antioestrogen-treated rats may have been the consequence of a diminution in the secretion of progesterone, stemming from atrophy of CL.

Both in pregnant rabbits and rats treated with the antioestrogen, there was embryo mortality. In the pregnant rats, $44 \%$ of foetuses were resorbing while, in rabbits, almost all the embryos showed signs of advanced degeneration. In view of the fact that the placental tissue exerts a luteotrophic effect not only in the rat but also in the rabbit (for reference see Deanesly, 1966), atrophy of the cL may be an indirect effect of the antioestrogen stemming from a reduction in the luteotrophic support from the placenta rather than the effect of interference with the action of oestrogen. Furthermore, a reduction in the number of GL observed in Exp. A may have been due to interference by the antioestrogen with ovulation. To obviate these complications, the experiment was repeated using pseudopregnant rabbits in which the treatment was initiated on Day 2, by which time ovulation will have occurred (Harper, 1963). Here again, both the numbers and size of the cL were less in the treated than in the control group (Exp. C). Essentially similar results were obtained when the experiment was repeated (Exp. D). These findings are thus fully consistent with earlier views that oestrogen plays a crucial role in the growth and functional maintenance of CL in rabbits (Robson, 1937) and rats (see Bogdanove, 1966).

The author is grateful to Miss Rosemary Chester for assistance in the conduct of these experiments.

\section{REFERENCES}

Bogdanove, E. M. (1966) Preservation of functional corpora lutea in the rat by estrogen treatment Endocrinology, 79, 1011.

DeAnessy, R. (1966) The endocrinology of pregnancy and foetal life. In: Marshall's Physiology of Reproduction, Vol. 3, p. 891. Ed. A. S. Parkes. Longmans Green, London.

Greenwald, G. S. \& Rothchild, I. (1968) Formation and maintenance of corpora lutea in laboratory animals. F. Anim. Sci. 27, Suppl. 1, 139.

HARPER, M. J. K. (1963) Ovulation in the rabbit; the time of follicular rupture and expulsion of the eggs in relation to injection of luteinizing hormone. F. Endocr. 26, 307.

Kunn, N. J. (1969) Progesterone withdrawal as the lactogenic trigger in the rat. F. Endocr. 44, 39.

Nalbandov, A. (1970) Comparative aspects of corpus luteum function. Biol. Reprod. 2, 7.

Rozson, J. M. (1937) Maintenance by oestrin of the luteal function in hypophysectomized rabbits. 7. Physiol., Lond. 90, 435. 